\title{
A poesia de António Jacinto
}

Rosely Zenker Barbosa Lopes ${ }^{1}$

RESUMO: Esta comunicação tem por objetivo realizar uma leitura crítica da obra Poemas (1961) de António Jacinto, poeta angolano, tendo como referência a visão de Frantz Fanon sobre a violência, especialmente, em seu livro intitulado Os condenados da terra (1961). A tensão social revelada nos versos e nas palavras de Jacinto em Poemas pode ser reconhecida a partir das análises dos livros de Fanon, na medida em que ele trata de forma contundente a estrutura política, econômica e social do colonialismo europeu em África.

ABSTRACT: This paper aims to accomplish a critical reading of the work Poems (1961), by the Angolan poet António Jacinto, based on Franz Fanon's point of view on violence, especially in his book The wretched of the earth (1961). It is possible to recognize the social tension revealed on Jacinto's verses and words in the light of Fanon's work as he treats, in a sharp way, the social, economic, and political structure of the European colonialism in Africa.

PALAVRAS-CHAVE: António Jacinto, Frantz Fanon, literatura angolana.

KEYWORDS: António Jacinto, Frantz Fanon, Angolan literature.

\section{Os passos de um intelectual engajado}

Não haverá movimento ou surto literário, iniciativa de carácter político de vulto em Angola, desde que lá de longe a idéia de libertação começou a germinar, onde este homem não tivesse intervindo. Manuel Ferreira

António Jacinto do Amaral Martins nasceu em Golungo Alto, Angola, em 1924. Publicou seu primeiro livro em 1961, Poemas (objeto de estudo do presente projeto). Fez parte do Movimento dos Novos Intelectuais de Angola, quando participou da Revista Mensagem como poeta e contista. Foi preso em 1961 pela Polícia Internacional de Defesa do Estado (PIDE), saindo do campo de concentração de Tarrafal, em Cabo Verde, apenas em 1972. Após a independência de Angola, em 1975, foi Ministro da Educação e da Cultura, entre outros cargos de destaque no governo. Foi também membro fundador da União dos Escritores de Angola. Faleceu em 1991.

\footnotetext{
${ }^{1}$ Mestranda em Estudos Comparados de Literaturas de Língua Portuguesa, FFLCH-USP. Pesquisa: Poéticas da violência em situação de colonização: Leitura crítica de António Jacinto e José Craveirinha. E-mail: roselyzenker@hotmail.com
} 
António Jacinto pertenceu a uma geração de intelectuais, chamada Geração de 50, que buscava a firmação dos valores nacionais; o reconhecimento de culturas até então discriminadas e ignoradas pela colonização; a independência do país; e influenciou as gerações consecutivas e destacou-se tanto como poeta, como homem público, recebendo várias homenagens e prêmios nacionais e internacionais.

Carlos Ervedosa nos ressalta características dos poetas desta época:

Os seus poemas trazem o aroma variado e estonteante da selva, os coloridos dos poentes africanos, o sabor agridoce dos seus frutos e a musicalidade nostálgica da marimba. Mas vêm também palpitantes de vida, com o cheiro verdadeiro dos homens que trabalham, o gosto salgado das suas lágrimas de desespero e a certeza inabalável na madrugada que sempre raia para anunciar o novo dia (ERVEDOSA, 1979, p. 107).

A Geração de 50 promoveu um verdadeiro movimento cultural e literário, com variadas repercussões, e evidenciou a necessidade de se criar uma arte de raízes nacionais, longe do exotismo colonial até então dominante nas criações artísticas consideradas artificiais e sem ligação com a realidade latente. Como nos elucida Rita Chaves (1999, p. 46): "Ao evitar os procedimentos que conduziriam ao exótico e/ou ao pitoresco, os poetas optam pela aproximação com a terra e a cultura angolanas numa relação produtiva que afasta a clicherização". Esta geração organizou um movimento que tinha como objetivo "estudar a terra que lhes fora berço, a terra que eles tanto amavam e tão mal conheciam", como nos fala Carlos Ervedosa (1979, p. 101), provocando manifestações literárias que buscassem valorizar as culturas locais, as aspirações de libertação nacional, a luta de combate pelo povo.

António Jacinto não se pouparia para se dedicar em vida e em obra em prol de sua comunidade, de seu país.

\section{Humanizar, libertar}

Uma vez que ninguém pode sem crime espoliar seu semelhante, escravizá-lo ou matá-lo, eles dão por assente que o colonizado não é semelhante ao homem. Jean-Paul Sartre, em prefácio de Os condenados da terra

Frantz Fanon, em seu livro Os condenados da terra, lança-nos suas idéias sobre o colonialismo europeu em África, tendo em vista sua vivência em Argélia como clínico- 
chefe do hospital psiquiátrico de Blidá-Joinville, bem como atuação política após sua deportação deste país em 1955. O livro é escrito em 1961, data também de sua morte por leucemia. Aos 36 anos, Fanon parte da vida deixando-nos um testemunho denunciador da violência e destruição, não somente proferidas pelos colonizadores, mas também por eles entranhadas nas sociedades africanas.

O livro nos descreve como o colonizador se apropriou de terras nos territórios de África, estabeleceu uma relação social de castas, definidas por raça. Para se colocar no topo da superioridade racial, e portanto, sócio-econômica, articulou uma despersonalização do negro e do árabe, através de imposição armada e violenta. Estabeleceu um verdadeiro processo de 'coisificação' daqueles que não tinham a cor de pele branca.

$\mathrm{O}$ colonizado, sentindo-se minoria enquanto maioria estatística, foi relegado à pobreza e à escassez. Sentiu a injustiça e a crueldade de perto: o colonizador tomado de uma espécie de aval para roubar e matar nunca se vê obrigado a justificar seus atos ou pagar por eles, enquanto colonizados vêem-se privados de direitos, dignidade e respeito. Mas não de desejos: "não há um colonizado que não sonhe pelo menos uma vez por dia em se instalar no lugar do colono" (1961, p. 29). Institui-se, portanto, um maniqueísmo social: o colonizado representa para o europeu um "mal absoluto" (1961, p. 31), desprovido de ética, valores, humanidade.

Oprimido e desvalorizado, o colonizado é alimentado de sentimentos de ódio, inveja, e por que não esperança de que a situação pode se reverter. Contudo, os povos oprimidos não se deixam descaracterizar, sentindo sim as conseqüências inevitáveis de tal assédio, mas desenvolvendo um processo de tomada de consciência para arquitetar a defesa.

É justamente aí que podemos reconhecer os poemas de Jacinto, que denuncia a injustiça social vigente, criando empatia com os oprimidos e acendendo o sonho da libertação. Movimento, aliás, condizente com seu tempo e com intelectuais contemporâneos, que estabeleceram como propostas, entre muitas outras, a resistência ao sistema dominante e vigente e a valorização da cor local, evidenciando, por exemplo, a oralidade.

É importante salientar que Jacinto escreveu o livro Poemas em época de ditadura Salazarista, em que havia grande repressão, com inclusive censura atuante.

Este apanhado de poemas diz muito sobre a estrutura social vivida em Angola dos anos 50. Sociedade que apresenta uma fachada de prosperidade baseada na dedicação e no 
trabalho duro e honesto. Mas há o musseque, há o contrato ${ }^{2}$, há a exploração, há a exclusão e imobilidade social e outros fatores que explicam o porquê das possibilidades dos brancos e impossibilidades dos negros. Uma violência não declarada e não assumida pela metrópole dita as regras das vias de ascensão do colono. Jacinto, para abordar o tema da violência, explora a linguagem poética, recorrendo à metáfora, à ironia, à onomatopéia, às alusões, a pistas em seus poemas que acabam por denunciar violência e tensão social latentes.

Há de se notar que em Jacinto se percebe a leveza de linguagem, evidenciando o falar popular e a marca da oralidade. Como nos explica Alfredo Margarido (1980, p. 291), Jacinto "submete o poema ao ritmo, dando assim à música o importante papel que lhe cabe nas sociedades negras. Neste caso a palavra do poema, sendo embora inicialmente portuguesa, africaniza-se, angolaniza-se, graças ao ritmo".

Buscar as palavras existentes para reinventá-las através da fonética, da sintaxe e da semântica, alcançando assim a originalidade do falar popular que identifica o povo angolano em questão, diferenciando-os do tradicionalismo lusitano, é, pois, um recurso poderoso do poeta que evidencia sua gente e sua terra. Por vezes, recorre-se ao quimbundo, língua de um dos povos de Angola, para não somente ressaltar o conteúdo apresentado, como também registrar as manifestações lingüísticas de sua localidade.

Para recalcar a violência e postular-se contra o discurso dominante da metrópole, busca na simplicidade e no cotidiano o retrato das injustiças que presencia, carregando para a literatura personagens populares, marginalizados, massas trabalhadoras.

No poema "Monangamba", por exemplo, há o recorte de um espaço rural, cujo destaque é dado ao eu-lírico que, vendo-se em situação de exploração, questiona seu posicionamento em uma sociedade que se move para atender unicamente as necessidades de seu opressor. Os primeiros versos identificam o homem ao seu produto de trabalho:

Naquela roça grande tem café maduro

E aquele vermelho-cereja

São gotas do meu sangue feitas seiva.

O café vai ser torrado,

\footnotetext{
${ }^{2}$ Entende-se por contrato, neste contexto, como "uma forma de exploração da força de trabalho angolana, que obriga os homens e as mulheres a abandonar o refúgio das aldeias, as formas de vida que eram as suas, para trabalharem em plantações ou nas indústrias dos brancos (...). Não admira, por isso, que o contrato seja descrito como uma forma mal disfarçada de trabalho forçado, tanto mais evidente quanto se sabe que a maioria dos proprietários angolanos procurou estar sempre aquém das normas administrativas, pagando pouco, muitas vezes ou quase sempre nada, alimentando mal e alojando pessimamente os trabalhadores" (MARGARIDO, 1980, p. 363).
} 
Pisado, torturado,

Vai ficar negro, negro da cor do contratado

Negro da cor do contratado!

A tomada de consciência se ressalta através de orações interrogativas durante o poema, cujo pronome "quem" repete-se de tal maneira enfática que pode ser interpretado como um desafio (“Quem se levanta cedo? quem vai à tonga?”). Desafia-se a negar uma sociedade colonial que estipula a violência como mola propulsora de dinâmica social. Percebemos, pois, a atitude de ironia perante as questões: quem mais, senão o colonizador, para estabelecer tais relações? Até mesmo as aves, os regatos, o vento são capazes de responder: "Monangambééé...".

Opõem-se o que cabe ao trabalhador e o que recebe o patrão: ao primeiro lhe restam desdém, fubá podre, peixe podre, panos ruins; ao segundo, dinheiro, máquinas, carros, senhoras, prosperidade. $\mathrm{O}$ que se distingue neste apanhado de coisas não é somente a diferença de bens materiais, notadamente o poder aquisitivo do patrão e a miséria do trabalhador, mas também os elementos humilhação/sentimento de superioridade.

Para Margarido, este poema é:

(...) o exame das essências do contrato e, também, a soma das alienações parciais que acabam por the desenvolver a consciência da sua miséria (...). O poema de António Jacinto pretende, naturalmente, ultrapassar o plano do descritivo, embora aprofundado, e apresenta-se como um trabalho de encorajamento, de educação, que o incita a desafiar as leis que o reduzem a uma servidão (MARGARIDO,1980, p. 279).

Se Fanon por um lado alerta que "o colonialismo não fez senão despersonalizar o colonizado" (1961, p. 254), por outro Jacinto deflagra o senso crítico, a resistência, a identificação lírica com a natureza, a capacidade de resiliência. Através da oralidade, o poema dá voz ao oprimido, para expressar o não-conformismo diante as injustiças sociais.

Para apontar as denúncias, é preciso desentranhar a poesia, confrontá-la com seu contexto histórico, encontrar ressonância com a situação de colonização de outros países de África. Optar por uma leitura crítica de Jacinto sob a contribuição de Frantz Fanon é aprofundar o entendimento, portanto, de seus versos, de suas palavras, de seu verbo. Porque Fanon explicitou com maestria o corpo do sistema colonialista, analisando a violência em situação de colonização européia em África. 
Sem dúvida, estes dois autores observam o fenômeno da violência sob o mesmo olhar: o do oprimido, não omitindo o sofrimento causado pela colonização e tampouco disfarçando a injustiça pronunciada pelas conquistas dos impérios europeus.

\section{Referências bibliográficas}

ANDRADE, Fernando da Costa, Literatura angolana (opiniões), Edições 70, 1980.

CHAVES, Rita. A formação do romance angolano, entre intenções e gestos. São Paulo: FBLP; Via Atlântica, 1999.

EVERDOSA, Carlos. Roteiro da literatura angolana. Lisboa. Edições 70. $2^{\text {a }}$ Edição. 1979.

FANON, Frantz. Os Condenados da Terra. $2^{\circ}$ ed. Rio de Janeiro: Civilização Brasileira, 1979

HAMILTON, Russel G. Literatura africana, literatura necessária. I-Angola. Tradução do autor. Lisboa, edições 70, 1981.

JACINTO, António. Poemas. Luanda: Edições Maianga, 2004.

LARANJEIRA, Pires, A Negritude Africana de Língua Portuguesa, Porto, Afrontamento, 1995.

LARANJEIRA, Pires. Literaturas africanas de expressão portuguesa. Lisboa: Universidade Aberta, 1995.

LEITE, Ana Mafalda, Oralidades e Escritas nas Literaturas Africanas, Lisboa, Colibri, 1998.

MACÊDO, Tania Celestino de. Angola e Brasil: estudos comparados. São Paulo: Arte \& Ciência, 2002.

MACÊDO, Tania Celestino de. "A representação literária de Luanda - uma ponte entre Angola, Brasil e Portugal". In Via Atlântica na 01. São Paulo; Bartira, 1997.

MARGARIDO, Alfredo. Estudos sobre literaturas das nações africanas de língua portuguesa. A Regra do Jogo, 1980.

MARGARIDO, Alfredo, A Lusofonia e os Lusófonos: Novos Mitos Portugueses, Lisboa, Edições Lusófonas, 2000.

MATA, Inocência, Literatura Angola: Silêncios e Falas de uma Voz Inquieta, Luanda, Kilombelombe, 2001.

MOURÃO, Fernando Augusto Albuquerque. A Sociedade angolana através da literatura. São Paulo, Ática, 1978.

MOURÃO, Fernando Augusto Albuquerque. Contistas africanos. Lisboa, Casa dos Estudantes do Império, 1960.

ROCHA, Jofre. Intervenções sobre literatura artes e cultura. Luanda, Kilombelombe, 2004.

SANTILLI, Maria Aparecida. Africanidade - contornos literários. São Paulo, Ática, 1985.

SEPULVEDA, Maria do Carmo \& SALGADO, Maria Teresa. África e Brasil: Letras em laços. Rio de Janeiro: Atlântica, 2000. 